Anyone who may still wonder whether Mr. Davidson's book actually explains a divine revelalation should open the volume at random; he will find endless numerological jugglings and fictitious lines drawn in the pyramid. What Divine Being ever conceived descended to such puerilities? Truth, on the other hand, is known by its simplicity. For Christians the Bible is good enough, without seeking for guidance in the structure of the Great Pyramid. But since Mr. Davidson quotes from the Bible in support of his theories, it is quite fair to quote against him from St. Mark's Gospel, xiii, 22: "For there shall arise false Christs and false prophets, and shall shew signs and wonders, that they may lead astray, if possible, the elect."

Rupert Gleadow.

\title{
Modern Street Lighting
}

$\mathrm{I}^{\mathrm{N}}$ his presidential address to the Junior Institution of Engineers delivered on December 14, Mr. C. C. Paterson chose as his subject "Modern Street Lighting", laying stress on the necessity of making roads safe for traffic. It is important to remember that the number of licensed road vehicles in Great Britain has more than doubled during the last ten years. Even with the reduced maximum speed of 30 miles an hour in street lighted areas, good illumination is required for safe driving during night time. The great source of danger is that the eye has to function in conditions in which there is so little light. The eye sees by contrast either of colour or brightness. If everything were of the same colour and uniformly bright, and the visibility of the atmosphere were perfect, it would be impossible to distinguish objects from their backgrounds as there would be no contrast.

The illumination produced by bright sunshine is of the order of 8,000 foot-candles. On an overcast day, daylight falls from about 700 f.c. to 100 f.c. just before dusk. About half an hour after the sun sets, the illumination is about 5 f.c. At this point a number of drivers switch on their lights, and about ten minutes later when the illumination is 2 f.c. about 60 per cent of the cars have their lights on. When the illumination falls to 1 f.c. seeing is bad and car sidelights are beginning to glare. As the light falls to $0 \cdot 1$ f.c. the contrasts which give such good discrimination in full day. light are very slight, and the elements of the retina which give us the sensation of colour are weakening in their action. A man with a brown jacket and grey trousers now appears to have clothes of a uniform dark colour, but we are unable to say what colour it is. The dark grey lorry which can be seen clearly by daylight against a somewhat lighter grey road surface now disappears, as the contrast is not sufficient.

The problem of good street lighting is to find how to make the contrasts sufficiently distinct. For good seeing, the maxim is to make contrasts as distinct as possible, and this leads to the simple rule "make the road surface as bright as possible". Street lamps from this point of view should not be designed to light up objects on the road, but the road itself. Objects on the street are usually seen as dark things against a bright background, and this is the effect which street lighting should enhance. It is often true that when we drive behind a motor headlight, we see because its horizontal beam lights up the object itself rather than the road. But this projector beam is $20-30$ thousand foot-candles, which is many times greater than would be possible under good street lighting conditions. For general street lighting, it would, taking expense into account, be impossible to make the objects brighter than the street.

The first step towards improving lighting is to make the road form a light background by means of its polish or shiny nature. Light can be directed on to the road in such a way that it reflects like a mirror. It does this when the light is directed along the road instead of on it. It is surprising what unpromising materials reflect light in this way. An asphalt road surface well polished by traffic reflects light excellently. A rough non-skid road surface does so also in a less degree. It is the same kind of effect as that produced by the moon when it shines towards us over water. Fortunately, as roads are at present surfaced, the conditions are often ideal for securing an uninterrupted bright path of light along their whole length. For an expenditure of three watts per foot run of road, we can obtain an illumination of 0.5 f.c. as seen on a white surface.

The two guiding principles used in modern street lighting are increasing the road brightness by specular (mirror) reflexion and increasing it by diffuse reflexion. The modern designer uses street illumination only as a rough guide to find the total amount of light available in the street. It is little use to specify road lighting by means of the 'minimum' illumination produced. Judging, as is usually done, the relative merits of two systems of lighting by the 'minimum' illumination produced is sometimes quite misleading. The real criterion is to find out which yields the highest road brightness with a given street surface condition.

If a road is so wet as to be like a still sheet of 
water, very little light is diffused, the chief road brightness coming apparently from the image of the lamp. So far, means have not been found of rendering visibility anything like as good under wet as under dry conditions.

The use of a large quantity of light merely to claim compliance with a higher class of specification of the British Standards Institution without ensuring that it gives a proportionally higher road brightness is wasteful. Competition in illumination is useless, but competition in road brightness is of real value and importance. However, it is inadvisable to skimp the light and reduce its amount to the minimum required for the road surface. A certain amount of light on buildings and fences makes a great difference to the appearance of the lighting effect and sometimes aids visibility.

Mr. Paterson's address contains much novel matter, and it looks as if our ideas on street lighting would be considerably modified in the next few years. To all who drive motor-cars or ride bicycles, a good road brightness is essential as safety depends on it. Only in this way can we safely eliminate the use of headlights and the risky situations which arise from their use on busy roads.

\section{Polarimetric Methods in Chemistry* \\ By Prof. T. M. Lowry, c.B.E., F.R.s.}

\section{Arrest of Mutarotation}

$\mathrm{F}^{\mathrm{u}}$ URTHER fortuitous observations showed that the mutarotation of nitrocamphor is not an independent intramolecular process, but depends on extramolecular circumstances, since under favourable conditions it may be arrested more or less completely over a period of several days. This discovery (which was made more than twenty years before Kurt Meyer's experiments on the aseptic distillation of ethyl acetoacetate in alkalifree vessels of silica glass) was also the result of a fortunate accident. The mutarotation of a solution of nitrocamphor in chloroform had been followed to completion during a period of about eight days, but had been accompanied by some loss of solvent (and possible concentration of the solution) by evaporation. The remainder of the solution had been left in the small graduated flask in which it had been prepared, and there was no reason to suspect that it would behave in any respect differently from the sample in the polarimeter tube. It was therefore a great surprise when, at the end of seventeen days, on attempting to confirm the final reading, it was found that the residue in the flask gave a rotation almost identical with the initial reading recorded more than a fortnight before. The transfer of the solution to the polarimeter tube, however, sufficed to initiate the mutarotation, which then proceeded with the same velocity as before.

Nearly ten years later, a further series of experiments was being made on the catalysis of mutarotation by acids and bases. It was then observed that solutions of nitrocamphor in chloroform, to which trichloracetic acid had been added, developed an intolerable and pungent odour. This observation showed that the peculiar inertness of chloroform was due to its oxidation to carbonyl

* Continued from p. 921. chloride or phosgene, and to the consequent elimination of traces of nitrogenous bases, in the form of inert carbamides. The same series of experiments had already shown that some of these bases have an amazing catalytic activity. Thus an acceleration of mutarotation was detected as a result of adding piperidine to benzene in the proportion of 1 part of the base in 10 million parts of the solvent. This acceleration was also one of the earliest examples of a phenomenon which has since become very familiar, namely, a catalysis by bases, which could not be attributed to the presence of hydroxyl ions, and was therefore outside the scope of the conventional theories of catalysis by acids and bases, as developed and used by Ostwald and his colleagues.

An immediate sequel to this discovery was the arrest in silica vessels of the mutarotation of solutions of nitrocamphor in benzene and in ether, to which traces of an anticatalyst had been added. Subsequent experiments showed that mutarotation could also be arrested in solutions of tetramethylglucose in chloroform, benzene, ethyl acetate and pyridine ; and Owen developed to a fine art the process of arresting, almost at will and with very few failures, the mutarotation of solutions of tetra-acetylglucose in dry ethyl acetate.

The climax of this work was reached when Faulkner found that the mutarotation of tetramethylglucose could be arrested both in cresol and in pyridine, but proceeded too rapidly for convenient observation in mixtures of these two solvents. Since these mixtures gave velocities of mutarotation which were much greater even than in water, it was clear that the essential factor in promoting mutarotation was not an oxygenated solvent, or an ionising solvent (as had been suspected at earlier periods), or even the ionisation 